\title{
Common polymorphisms in MTHFR and prothrombin gene in iranian women with abortions at different ages
}

\begin{abstract}
Background and objectives: Abortion is considered as one of the most important problems in pregnancy and a multifactorial disease that both genetic and environmental factors influence on it. There is no known reason for $50 \%$ of abortion cases. Factor 2 (Prothrombin) is one of the 12 clotting proteins with important role in creating thrombophilia in women with abortion. In this study, we investigate the association between gene polymorphisms like C677T and A1298C of MTHFR gene and G20201A polymorphism of prothrombin gene as probable abortion markers.
\end{abstract}

Methods: In this study, 235 women with a history of abortion as patient group and 250 women with no history of abortion with at least 2 successful fertility as control group were randomly selected. ARMS PCR was used to amplify gene areas containing the polymorphisms of MTHFR and prothrombin genes using gene specific primers.

Results: The highest abortion rate was detected inpatients' group over 31 years old with a frequency of $38 / 3 \%$ and the lowest number of abortions was seen in a group age under 20 years old patients with a frequency of $14 / 9 \%$.Evaluation of genotypes GG and GA of G20201A polymorphism between the two groups was not statistically significant. While the combination of $\mathrm{T}$ allele of C677T variant and G allele of G20201A variant yielded statistically. Combination of Allele of A1298C variants and G allele of G20201A variants were associated. This study showed that two A1298C and C677T polymorphisms of MTHFR gene were associated with abortion while G20201A polymorphism has no relationship with the disease.

Keywords: Miscarriage, Idiopathic abortion, Thrombophilia, Polymorphisms, Prothrombin Methylene tetra hydro Folatereductase
Volume 8 Issue 2 - 2017

\author{
Sahel Towfigh Rafiei,' Taher Mohammadian, ${ }^{2}$ \\ Hossein Rasi ${ }^{3}$ \\ 'Department of biology, Islamic Azad University, Iran \\ ${ }^{2}$ Department of microbiology, Islamic Azad University Shahr-e- \\ Qods, Iran \\ ${ }^{3}$ Department of biology, Islamic Azad University, Iran
}

Correspondence: Taher Mohammadian, Department of microbiology, Islamic Azad University Shahr-e-Qods, Iran, Email tmohammadian@yahoo.com

Received: August 24, 2017 | Published: November 21, 2017

\section{Introduction}

Fertility problems affect a large number of couples throughout the world.One of the most common form of these problems is abortion. ${ }^{1,2}$ Miscarriage is known as the termination of pregnancy before the fetus development completes and be able to survive. ${ }^{3}$ Abortions are divided into induced abortions and spontaneous abortions where abortion without medical or mechanical interventions for uterine evacuation is carried out it is called spontaneous abortion. ${ }^{4}$ Spontaneous pregnancy loss is very common and identification of those genetic polymorphisms associated with abortion for indication of at risk people and risk assessment in genetic counseling can help in early diagnosis and reduce the disease rate. ${ }^{5}$ Spontaneous abortion may physically and emotionally affect couples especially when they are faced with recurrent fetuses 'loss. In couples where the women are over 35 and men are over 40 years old, the risk of miscarriage is the highest. ${ }^{6}$ Numerous factors include genetic, immunological, anatomical, infectious, environmental and endocrine factors, age and hematological disorders provide abortion (Table 1). Based on reports, chromosomal abnormalities are involved in 50\% to $80 \%$ of the pregnancy loss cases and their influence depends on the reproductive age and pregnancy age at abortion time. ${ }^{7}$ Single-gene disorders could be analyzed by family history study and achieving particular hereditary pattern of an anomaly or a syndrome. ${ }^{2}$ Although abortion has a variety of reasons, but still more than $50 \%$ of cases remain idiopathic which is a controversial issue for both patients and clinicians? It was suggested that one of the possible reasons for abortion is thrombophilia, a relatively common disorder. ${ }^{8}$ The disease inherits or acquires inhibitory proteins in the coagulation cascade and subsequent occurrence of thrombosis or hypercoagulable due to misplaced clots. ${ }^{9}$ One of the factors that induce thrombophilia is hereditary defect due to the presence of factor 2, 5 and 13 polymorphisms. ${ }^{8}$ More than 50 important factors affect blood clotting, some as coagulation materials which promote coagulation and some as anticoagulant which inhibit coagulation. Among 12 proteins known as coagulation factors, factor 2convertsprothrombin to thrombin which in term converts fibrinogen into fibrin to form a clot (10). On the other hand, Foliate one of the B vitamins, soluble in water and in cell acts as a cofactor for pyrine and thymidine synthesis and the synthesis of methionine from homocysteinemia. Foliate has a critical mechanism for proper fetal growth and metabolism. ${ }^{11}$ Lack of vitamin B can lead to mild hyper homocysteinemia. ${ }^{12}$ Increased concentrations of homocysteinemia are considered as a reason for failure in the vascularization of chorionic villi. ${ }^{11}$ Homocysteinemia is converted to methionine and re-methylated using Foliate as a methyl donor (13). When there are elevated levels of plasma homo cysteine, a risk factor for deep vein thrombosis, hyper homocysteinemia or thrombophilia occur. ${ }^{14}$ Thrombophilia disorders during pregnancy significantly increase the risk of venous thrombosis and induce susceptibility to vascular complications during pregnancy and are good reasons for serious obstetric complications including recurrent miscarriage, fetal growth retardation, preeclampsia and placental in 1 to 5 percent of women. ${ }^{15}$ 
Table I The etiology of abortion ${ }^{2}$

\begin{tabular}{|c|c|}
\hline \multirow{6}{*}{ Genetic causes } & Aneuploidy \\
\hline & Somatic \\
\hline & Sex chromosome \\
\hline & Mendelian disorders \\
\hline & Multifactorial disorders \\
\hline & Parental chromosomal (sullivan et al.2004) \\
\hline \multirow{3}{*}{ Immunologic causes } & Autoimmune causes (festin,etal.2007) \\
\hline & Alloimmune causes (porter and scott 2000) \\
\hline & Uterine mullerian anomaly \\
\hline \multirow{8}{*}{ Anatomic causes } & $\begin{array}{l}\text { Uterine septum (the anomaly most commonly } \\
\text { associated with pregnancy loss) }\end{array}$ \\
\hline & Hemiuterus (unicomuate uterus) \\
\hline & Bicomuate uterus \\
\hline & Diethylstilbestrol-linked condition \\
\hline & Acquired defects (eg,asherman syndrome) \\
\hline & Incompetent cervix \\
\hline & Leiomyomas \\
\hline & Uterine polyps (saravelos and cocksedge 2010) \\
\hline \multirow[t]{2}{*}{ Infectious causes } & $\begin{array}{l}\text { Listeria monocytogenes, toxoplasma } \\
\text { gondii, rubella, herpes simplex virus (hsv), } \\
\text { measles, cytomegalovirus and coxsackieviruses. } \\
\text { (ford and schust 2009) }\end{array}$ \\
\hline & Smoking \\
\hline \multirow[t]{3}{*}{ Environmental } & Excessive alcohol consumption \\
\hline & Caffeine ( vibeke 2003 ) \\
\hline & Diabetes mellitus \\
\hline Endocrine factors & $\begin{array}{l}\text { Antithyroid antibodies } \\
\text { Luteal phase deficiency ( arredondo and noble } \\
2006 \text { ) }\end{array}$ \\
\hline Hematologic disorders & Thrombophilia ( robertson et al. 2006 ) \\
\hline
\end{tabular}

Wasim Almawi et al. 2002 determined the prevalence of the G20210A genetic variant in factor 2 and G1691A genetic variant in factor 5 was several times higher in women with a history of abortion than those of control population with no miscarriage report. ${ }^{16}$ Ti Zhang et al. 2013 in a meta-analysis examined the relationship between five genetic variants in foliate pathway including C677T in MTHFR gene, A1298C in MTHFR gene, A2756G in MTR gene, A66G in MTRR gene, A80G in RFC1 gene and the risk of neural tube defects (NTDs). In this study, significant associations between C677T in MTHFR and A80G in RFC1 variants with increased risk of NTDs were observed, but other variants of Foliate pathway did not show a significant association with the risk of NTDs. ${ }^{17}$ In another study, HizemSondes et al. 2005 determined that the relationship between G20201A polymorphism in factor 2gene and G1691A polymorphism in factor 5 genes had unpleasant pregnancy consequences in women with idiopathic abortion where G1691A polymorphism with resistance to protein $\mathrm{C}$ is more prevalent. ${ }^{18}$ The aim of this study was to investigate the relationship between the polymorphisms with abortion as genetic risk factors for miscarriage. The results of this study in larger population could be used in early diagnosis and timely treatment of idiopathic abortion.

\section{Material and methods}

\section{Sampling}

In this case-control study, a population of 235 patients (women with idiopathic abortions) with at least one consecutive abortion and no record of live birth who were referred to women Kamali Hospital of Karaj formed the case group. The control group included 250 women with a history of no miscarriages, stillbirths and/or infertility with at least one healthy child, with no experience of assisted reproductive technology (ART). Demographic information of the individuals of both group including family marriage, blood type, family history of abortion, marriage age were considered to match the under study groups (Table 2). The results of the genotyping of each polymorphism were analyzed by SPSS software and Chi-square test.

Table 2 Patients' demographic information's

\begin{tabular}{lll}
\hline Demographic information & Control Group (Percentage) number Patient group (Percentage)number \\
\hline Family marriage & $(6 \%) 15$ & $(29.7 \%) 70$ \\
Family history of abortion & $(18 \%) 45$ & $(36.1 \%) 85$ \\
Abortion Number & & \\
Once & - & $80(\% 34.08)$ \\
Twice & - & $140(\% 59.75)$ \\
Three times & & $15(\% 6.39)$ \\
Blood Type & $(12.77 \%) 30$ & \\
A+ & $(34.04 \%) 80$ & $(21.28 \%) 50$ \\
A- & $(8.51 \%) 20$ & $(8.51 \%) 20$ \\
B+ & - & $(12.77 \%) 30$ \\
B- & $(21.28 \%) 50$ & $(4.25 \%) 10$ \\
AB+ & $(8.51 \%) 20$ & $(10.64 \%) 25$ \\
AB- & $(8.51 \%) 20$ & - \\
O+ & $(12.77 \%) 30$ & $(34.04 \%) 80$ \\
O- & & $(8.51 \%) 20$ \\
\hline
\end{tabular}

\section{DNA extraction}

From each individual, $5 \mathrm{ml}$ of peripheral blood was taken after physical examination and review of clinical records and verification of unknown to abortion. DNA was extracted using an extraction kit (Cinagen, cat\# DN8215C) according to manufacturer's instructions. For this purpose, first, all products of kit were warmed up to the room temperature. Lysis buffer was located inside a $37^{\circ} \mathrm{C}$ Hot Plate for 10 minutes. For each sample, $100 \mu 1$ of blood was transferred into a micro tube, $700 \mathrm{ml}$ of lysis buffer was added and placed in a term bloc, and then vortexed for 15 seconds until sample was homogenized. Then, we added $500 \mathrm{ml}$ of precipitation buffer, vortexed and centrifuged at $12000 \mathrm{xg}$ for 5 minutes. The supernatant was disposed, $100 \mathrm{ml}$ of washing buffer was added to the palate, vortexed and centrifuged (2 times) each time, we disposed the supernatant, kept the palate which was placed inside the term bloc for 5 minute and finally the solvent buffer was added to and centrifuged for 30 second. Finally, the 
supernatant containing DNA that was used for PCR and electrophoresis analysis. All individuals of two groups gave written consent.

\section{Primer design}

Reference sequence of MTHFR and Prothrombin genes were selected from the articles. The genes' sequences containing C677T, A1298C and G20201A polymorphisms were identified by NCBI genome browser. The gene specific primers were selected from the primer 3 website and confirmed by primer blast, NCBI, and then the primers were ordered to be synthesized (Cinagen Company, TehranIran).

\section{ARMS PCR}

Genetic variant analysis was performed as following: For C677T polymorphism, two reactions were used for each sample where primer C as forward primer (5'TGC TGT TGG AAG GTG CAA GAT3') and primer $\mathrm{N}$ as the reverse primer (5'GCG TGA TGATGA AAT CGG3') were used in the first reaction. In the second reactions, forward primer was used together with primer $\mathrm{M}$ asthereverse primer (5'GCG TGA TGATGA AAT CGA3'). For A1298C polymorphism detection, primer C (5'CCT TTG GGG AGC TGA AGG ACT ACT AC3'), primer N (5'CAA AGG ACT TCA AAG ACA GTC3') and primer M (5'GGT AAA GAA CAA AGA CTT CAA AGA CAC TGT G3') were used. For amplification of the gene region containing G20201Apolymorphism (5'TCT AGA AAC AGT TGC CTG ACA G3'), (5'GCA CTG GGA GCA TTG AGG ATC3'), (5'GCA CTG GGA GCA TTG AGG ATT3') oligonucleotides were used as primer $\mathrm{C}$, primer $\mathrm{N}$ and primer $\mathrm{M}$ to amplify the target region containing the polymorphisms (Table 3 ). Each reaction contained100ng template DNA, $200 \mathrm{mM}$ of each primer, $9 \mu 1$ master mix (Taq DNA Polymerase, PCR Reaction Buffer, and $2 \mathrm{Mm} \mathrm{Mgcl2}$ ) with a total volume of $25 \mu 1$. Reactions were performed using diagnostic kit (Cinagen, cat\# PR8251C) to predict genetic variants based on the protocol. PCR program was as following: The first denaturationat $96^{\circ} \mathrm{C}$ for 2 minutes, and then 30 cycles of denaturing at $96^{\circ} \mathrm{C}$ for 30 seconds, annealing at $63^{\circ} \mathrm{C}$ for $1 \mathrm{~min}$, extension at $72^{\circ} \mathrm{C}$ for $1 \mathrm{~min}$., and a final extension at $72^{\circ} \mathrm{C}$ for 30 second, respectively. To check the quality of extracted DNAs and desired PCR products, we used agarose gel electrophoresis (BIORAD) and spectrophotometry. The results were analyzed by SPSS (version 19 (and statistical tests such as Fisher-exact test and Chi-Squaretest.

Table 3 Primer sequence used in this study

\begin{tabular}{|c|c|c|c|}
\hline Polymorphism & Type and sequence of primers & Annealing temperature & Sequence length \\
\hline MTHFR & Frw:5-TGC TGT TGG AAG GTG CAA GAT-3 & Recommended: & C/T: \\
\hline$(\mathrm{C} 677 \mathrm{~T})$ & $\operatorname{Rev}(\mathrm{W}): 5-G C G$ TGA TGATGA AAT CGG-3 & $63-2$ & $W^{*}: 226 \mathrm{bp}$ \\
\hline $\mathrm{C}>\mathrm{T}$ & $\operatorname{Rev}(M): 5-G C G$ TGA TGATGA AAT CGA-3 & 60 & $M^{*}: 226$ bp \\
\hline MTHFR & Frw:5-CCT TTG GGG AGC TGA AGG ACT ACT AC-3 & Recommended: & A/C : \\
\hline$(\mathrm{A} / 298 \mathrm{C})$ & $\operatorname{Rev}(W): 5-C A A$ AGG ACT TCA AAG ACA GTC-3 & 65 & $W: 120 \mathrm{bp}$ \\
\hline$A>C$ & $\operatorname{Rev}(M): 5-G G T$ AAA GAA CAA AGA CTT CAA AGA CACTGT G-3 & 61 & M: 127 bp \\
\hline Prothrombin & Frw: 5-TCT AGA AAC AGT TGC CTG ACA G-3 & Recommended: & G/A : \\
\hline ( G2020IA) & $\operatorname{Rev}(\mathrm{W}): 5-G C A$ CTG GGA GCA TTG AGG ATC-3 & 60 & $W: 320 \mathrm{bp}$ \\
\hline $\mathrm{G}>\mathrm{A}$ & $\operatorname{Rev}(M): 5-G C A$ CTG GGA GCA TTG AGG ATT-3 & 55 & $M: 320$ bp \\
\hline
\end{tabular}

$\mathrm{W} *$ wild genotype

$M *:$ Mutant genotype

\section{Results}

To calculate the frequency of polymorphic genotypes, samples were classified into two groups. The results of each group were separately analyzed by Chi-Square test and their significance level was determined. The results indicated a significant association between C677T polymorphisms and abortion.CC, CT, TT genotypes respectively had 0,0026/0, 004/0 P-value (Table 4). A1298C polymorphism also was associated with abortion. AA, AC, CC genotypes respectively indicated 0, 00025/0 , 0/039 P-value (Table 5). The genotype frequency of G20201Apolymorphism, showed no significant relationship to abortion. GG, GA genotypes had 0/071, 0/072 P-value (Table 6).In order to classify patients, total of 4 groups was identified. According to survey, the lowest number of abortions was found to be in the age group fewer than 20 with frequency of 14.9 percent and the highest number of abortions was found in the age group over 31 years old with frequency of 38.3 percent.

Table 4 The results of genotypic C677T polymorphism in patients and controls

\begin{tabular}{lllll}
\hline Genotype & Control Group (Percentage) number & Patient group (Percentage) number & P-Value & Odd ratio \\
\hline CC & $190(\% 76)$ & $100(42 \%)$ & $000 / 0$ & $(44 / 0-12 / 0)$ \\
CT & $35(\% \mid 4)$ & $75(32 \%)$ & $0026 / 0$ & $(19 / 6-35 / 1)$ \\
TT & $25(10 \%)$ & $60(26 \%)$ & $004 / 0$ & $(37 / 7-31 / 1)$ \\
Total & 250 & 235 & &
\end{tabular}

Table 5 The results of genotypic A 298 C polymorphism in patients and controls

\begin{tabular}{lllll}
\hline Genotype & Control Group (Percentage) number & Patient group (Percentage) number & P-Value & Odd ratio \\
\hline AA & $175(\% 70)$ & $85(\% 36)$ & $000 / 0$ & \\
AC & $60(\% 24)$ & $115(\% 49)$ & $00025 / 0$ & $(81 / 5-59 / 1)$ \\
CC & $15(\% 6)$ & $35(\% / 5)$ & $0 / 039$ & $(34 / 8-93 / 0)$ \\
Total & 250 & 235 & & \\
\hline
\end{tabular}


Table 6 The results of genotypic G2020IA polymorphism in patients and controls

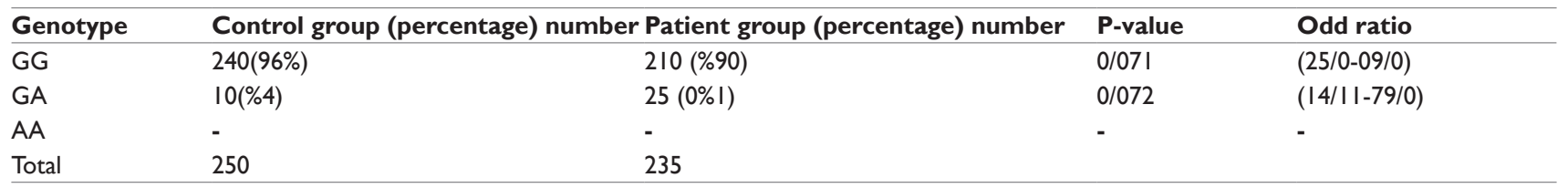

\section{Discussion}

One of the major problems of pregnancy is miscarriage or RPL (Recurrent Pregnancy Loss). The most common types of abortion is spontaneous miscarriage with two or more sequential fetus loss. So far, several factors such as genetic disorders, hormonal, anatomical, oxidative stress, and environmental factors have been identified that are introduced as decisive and influential recurrent miscarriage reasons. ${ }^{1}$ Among genetic variants involved in abortion, alterations in blood coagulation factors are reported to be important. ${ }^{10}$ In this study, the most common variant of coagulation factor 2 that is called Prothrombin and frequently reported genetic variant of the MTHFR gene were studied. G20201A genetic variant of coagulation factor 2 causes a defect in blood coagulation pathway which causes clots or thrombosis in the veins..$^{10}$ Following to the change in the protein and as the miscarriage, while there are other reports that reject the relationship between this polymorphism and abortions. ${ }^{16-18}$ Indeed, controversies in different studies could be related to the differences in the number of studied patients, differences in selective criterias and/or race of the target population. ${ }^{20}$ GihanGawish et al . in 2013 their molecular analysis of G1691A and G20210Agenetic variants in Saudi Arabia was performed on 72 patients with abortion history and 70 subjects as control group. Their result indicated G20210A genetic variant was found to be comparable to G1691A genetic variant in the patient group; both variants were more frequent in patient group than in the control group. Also the frequency of G1691A genetic variant in patients with preterm abortions and the frequency of G20210A variant were higher in patients with late-onset abortions (19). However, the results of our study showed that there was no significant relationship between G20201A polymorphism and abortion. Another study which was conducted by Rai and colleagues in 2006, they checked three genetic variants in thrombophilia include Prothrombin (G20201A), MTHFR (C677T) and Leiden (G1691A) among 357 Caucasian couples with RM and 68 parous Caucasian couples with no history of miscarriage. They confirmed that the frequency of each variant alone in patient and control groups was almost the same, but presence of 3 genetic variants at the same time in patient group increases risk of miscarriage. ${ }^{20}$ The results of our study were somewhat similar to their results. Folic acid and homocysteinemia are one-carbon molecules of foliate metabolism that maintain pregnancy. ${ }^{23}$ Foliate is required for DNA synthesis and cell division, so foliate is a key factor for rapid growth of tissues such as placenta. ${ }^{22}$ Pregnancy itself is a risk factor for thrombotic, so when it is combined with hyper homocysteinemia, an important risk for thromboembolic events forms. ${ }^{24}$ There is growing evidence to suggest that infertility could be the result of mothers vitamin B to be set. ${ }^{25}$ S Jill James et al. in 1999 studied the C677T polymorphism of MTHFR gene in 57 mothers of children with Down syndrome and also in 50 age-matched mothers as control group. The ratio of plasma homocysteinemia to methionine and toxicity of methotrexate lymphocytes were measured as the function of foliate status indication. The study showed that foliate metabolism in mothers of children with Down syndrome was abnormal and this may be due to a genetic variant in MTHFR gene [2 1 ]. The results of our study also indicated the association between C677T polymorphism and abortion.
Yunlei Cao and colleagues in 2014 investigated the relationship between polymorphisms of genes involved in folic acid metabolism and abortion. In their case-control study, C677T and A1298C polymorphisms of MTHFR gene, $\mathrm{A} 66 \mathrm{G}$ polymorphism in methionine syntheses reeducates gene, G80A and C696T polymorphisms of SLC19A1gene in 82 women with abortion and 166 healthy women were studied. They recognized significant associations between A1298C polymorphism of MTHFR gene and abortion [2 2 ]. Haplotype analysis indicated that combinations of allele C677T of MTHFR gene and A1298C allele of MTHFR gene is associated with abortion. Also, they showed that the combinations of allele A1298C of MTHFR and allele C677T of the same gene and 80G SLC19A1 and 696C SLC19A1 in patients with abortion have less frequencies [2 2 ]. The results of our study was contrary to their results. In our study, the presence of two polymorphisms (A1298C, C677T) simultaneously in one patient indicated significant associations with abortion. Given the high incidence of these polymorphisms in abortion, we may probably able to use the three above mentioned polymorphisms as molecular markers for early detection and timely treatment of patients prone to miscarriage. However, to be able to report the genetic variants as new markers for abortion, a larger study population is needed to repeat the experience. $^{26}$

\section{Acknowledgements}

No Acknowledgement.

\section{Conflicts of Interest}

No conflict of Interest.

\section{References}

1. Chaithra P, Malini SS, Kumar CS. An Overview of Genetic and Molecular Factors Responsible for Recurrent Pregnancy Loss. Int $J$ Hum Genet. 2011;11(4):217-225.

2. Ford HB, Schust DJ. Recurrent pregnancy loss: etiology, diagnosis, and therapy. Rev Obstet Gynecol. 2009;2(2):76-83.

3. Carrington B, Sacks G, Regan L. Recurrent miscarriage: pathophysiology and outcome. Curr Opin Obstet Gynecol. 2005;17(6):591-597.

4. Rai R, Regan L. Recurrent miscarriage. Lancet. 2006;368(9535):601611

5. Rull K, Nagirnaja L, Laan M. Genetics of recurrent miscarriage: challenges, current knowledge, future directions. Front Genet. 2012;3:34.

6. de La Rochebrochard E, Thonneau P. Paternal age and maternal age are risk factors for miscarriage; results of a multicentre European study. Hum Reprod. 2002;17(6):1649-1656.

7. van Niekerk EC, Siebert I, Kruger TF. An evidence-based approach to recurrent pregnancy loss. South African Journal of Obstetrics and Gynecology. 2013;19(3):61-65.

8. Greer IA. Thrombophilia: implications for pregnancy outcome. Thromb Res. 2003;109(2):73-81. 
9. Kovalevsky G, Gracia CR, Berlin JA, et al. Evaluation of the association between hereditary thrombophilias and recurrent pregnancy loss: a meta-analysis. Arch Intern Med. 2004;164(5):558-563.

10. Nelen WL, Blom HJ, AP STEEGERS E, et al. Homocysteinemia and Foliate levels as risk factors for recurrent early pregnancy loss. Obstet Gynecol. 2000;95(4):519-524.

11. Nair RR, Khanna A, Singh K. MTHFR C677T polymorphism and recurrent early pregnancy loss risk in north Indian population. Reprod Sci. 2012;19(2):210-215

12. Altmäe S, Stavreus-Evers A, Ruiz JR, et al. Variations in Foliate pathway genes are associated with unexplained female infertility. Fertil Steril. 2010;94(1):130-137 .

13. Den Heijer M, Koster T, Blom HJ, et al. Hyperhomocysteinemia as a risk factor for deep-vein thrombosis. N Engl J Med. 1996;334(12):759-762 .

14. Stover PJ. Physiology of Folate and vitamin B12 in health and disease. Nutr Rev. 2004;62(s1):S3-S12.

15. Wagner C. Biochemical role of Foliate in cellular metabolism. Foliate in health and disease. 1995;18(3):23-42.

16. Gregory JF. Case study: Foliate bioavailability. J Nutr. 2001;131(4 Suppl):1376S-1382S.

17. Finan RR, Tamim H, Ameen G, et al. Prevalence of factor V G1691A(Factor VLeiden)and Prothrombin G20210A Gene Variant in a Reccurent Miscarriage Population. Am J Hematol. 2002;71(4):300-305.

18. Zhang T, Lou J, Zhong R, Wu J, Zou L, et al. Genetic variants in the Folate pathway and the risk of neural tube defects: A meta-analysis of the published literature. PLoS One. 2013;8(4):e59570.
19. Mahjoub T, Mtiraoui N, Tamim H, et al. Association between adverse pregnancy outcomes and maternal factor V G1691A(Leiden)and Prothrombin G20210A genotypes in women with a history of recurrent idiopathic miscarriages. Am J Hematol. 2005;80(1):12-19.

20. Gawish GE. Molecular Characterization of Factor V Leiden G1691A and Prothrombin G20210A genetic variants in Saudi Females with Recurrent Pregnancy Loss. Biochem Genet. 2013;49(9-10):601-610.

21. Jivraj S, Rai R, Underwood J, et al. Genetic thrombophilicvariants among couples with recurrent miscarriage. Human Reproduction. 2006;21(5):1161-1165.

22. James SJ, Pogribna M, Pogribny IP, et al. Abnormal Folate metabolism and genetic variant in the methylenetetrahydroFolatereductase gene may be maternal risk factors for Down syndrome. Am J Clin Nutr 1999;70(4):495-501.

23. Cao Y, Zhang Z, Zheng Y, et al. The association of idiopathic recurrent early pregnancy loss with polymorphisms in folic acid metabolismrelated genes. Genes Nutr. 2014;9(3):1-8.

24. Laanpere M, Altmäe S, Stavreus-Evers A, et al. Folate-mediated onecarbon metabolism and its effect on female fertility and pregnancy viability. Nutr Rev. 2010;68(2):99-113.

25. George L, Mills JL, Johansson AL, et al. Plasma Folate levels and risk of spontaneous abortion. Jama. 2002;288(15):1867-1873.

26. Haggarty $\mathrm{P}, \mathrm{McC}$ allum $\mathrm{H}, \mathrm{McBain} \mathrm{H}$, et al. Effect of B vitamins and genetics on success of in-vitro fertilisation: prospective cohort study. Lancet. 2006;367(9521):1513-1519. 